\title{
Sobre performance e historicidade: uma abordagem estética e cultural da MTV Brasil
}

Juliana Freire Gutmann

\section{Resumo}

0 artigo apresenta uma proposta de articulação conceitual para a apreensão, em uma perspectiva histórica, do desempenho da MTV Brasil, seus modos de fazer, de se relacionar com a audiência e contextos culturais, processo aqui traduzido pela ideia de performance televisiva. Examina a emissora enquanto uma ambiência de experiência televisual, constituída por um contínuo processo de disputas por valores e sentidos, por continuidades e rupturas materializadas em seus programas e nos modos de convocação de marcas de gênero (televisivos e musicais). Projeta-se aqui uma expectativa mais ampla de pesquisa: discutir procedimentos para a análise de uma organização midiática, pela articulação entre os conceitos de gênero, performance e estrutura de sentimento, como possibilidade de promover diálogo entre a estética e os estudos culturais.

\section{Palavras-Chave}

Performance. Historicidade. MTV Brasil.

\section{A proposição}

Ao longo dos 27 anos de exibição no país, a MTV Brasil atou não apenas como meio de difusão fonográfica, função diluída ao longo da sua história, mas como espaço de experiências que instituiu expectativas em relação ao consumo audiovisual e musical. Junto à capacidade de ser reconhecida enquanto "canal da juventude", incorporou gostos e desejos do público, captou padrões de consumo, fazendo de suas materialidades membrana de acesso a dimensões da sensibilidade de uma determinada cultura. Ao forjar formas de desfrutar a música e 0 audiovisual em sintonia com os contextos televisivos e fonográficos brasileiros, fez do desenvolvimento tecnológico dispositivo da sua própria visualidade. Ainda que se reconheça a importância do canal no país, para o fomento da música popular massiva e da produção televisiva nacional, são poucas as referências acadêmicas voltadas para a análise de sua produção simbólica em uma perspectiva histórica ${ }^{1}$.

A abordagem histórica que se pretende da MTV Brasil - ou de qualquer outra organização
Professora do Programa de Pós-Graduação em Comunicação e Cultura Contemporâneas da Universidade Federal da Bahia - UFBA. 
televisiva - toma suas marcas expressivas enquanto espaços de interação entre estratégias de produção e contextos de recepção. Espaços pelos quais podemos apreender os modos de formar da emissora, suas formas específicas de atuar e ser reconhecida, processo aqui traduzido pela ideia de performance televisiva. A MTV Brasil é, então, tomada como pressuposto empírico para a investigação de como uma emissora constituiu um ambiente de experiência que também diz sobre um horizonte de expectativa (KOSSELLECK, 2006).

Em termos teóricos, propõe-se acionar os conceitos de gênero midiático, performance e estrutura de sentimento para o exame, em uma perspectiva histórica, das dimensões sensível e cultural de um canal televisivo, suas estratégias de produção e formas de reconhecimento. Tais conceitos, mesmo advindos de tradições distintas, podem se mostrar profícuos quando aplicados de modo articulado.

Em um sentido mais amplo, a proposição explicita o desejo de construir pontos de aproximação entre os estudos culturais e a estética para a análise histórica de fenômenos midiáticos.

A abordagem prevê a aproximação entre a noção de performance apropriada por Richard Schechner e Paul Zumthor e formulações dos estudos culturais importantes para pensar os fenômenos comunicacionais em uma perspectiva histórica e cultural, especialmente as noções de estrutura de sentimento, de Raymond Williams, e de gênero, de Jason Mittell. A preocupação com as estruturas estáveis e que também são transitórias (dos gêneros televisivos, da emissora, dos programas, das narrativas, dos usos da linguagem) para pensar um processo histórico encontra força teórica na hipótese cultural de Williams, denominada estrutura de sentimento. Mittell é convocado pela maneira como entende gênero enquanto categoria cultural que opera no interior das obras, através das lógicas industriais, da recepção e crítica cultural, regulando práticas de produção e de consumo. Já o conceito de performance parece acenar para a possibilidade de compreender o "mostrar fazer" (SCHECHNER, 2006) de uma emissora de TV, seu específico modo de formar executado através da sua produção audiovisual e cujo sentido se faz na relação (entre programas, seus contextos, suas recepções).

0 exame de parte do processo de formação da primeira emissora segmentada do país, com foco na dimensão da performance televisiva, é feito no marco de materialidades televisuais (cenários, corpos dos apresentadores, programas, vinhetas) e modos de valoração, os quais vão sendo alterados na relação com contextos e tempos históricos. Em uma perspectiva metodológica, a abordagem supõe um protocolo de análise que

No campo da comunicação brasileiro, há estudos relevantes sobre a MTV dedicados à análise das estratégias de linguagem da emissora, com foco nos seus comerciais e vinhetas (MUANIS, 2010), da chamada "estética do videoclipe" por ela empreendida ou do "gênero videoclipe" por ela institucionalizado (SOARES, 2009; TREVISAN, 2009; HOLZBACH, 2013), do "processo de aculturação" da expansão da marca multinacional no país (LUSVARGHI, 2002), de momentos episódicos de sua programação com foco em determinados programas (GUTMANN, 2005; REIS, 2006) etc. 
contempla relações entre textos, paratextos e contextos (GUTMANN, 2014) e privilegia um olhar historicizado do canal televisivo, visto enquanto ambiência, buscando dar conta do seu caráter cultural e sensível. As análises consideram os programas televisivos e os discursos que circularam sobre eles em reportagens e críticas.

\section{Gênero midiático, estrutura de sentimento e performance}

0 esforço de construir relações entre perspectivas teóricas oriundas da estética e dos estudos culturais se vale, a princípio, das noções de estrutura de sentimento, gênero midiático e performance para a compreensão dos processos comunicativos construídos historicamente por uma emissora de TV. 0 olhar se volta para 0 espaço de interação criado entre programas, sujeitos e seus contornos recepcionais, que nos permite falar da experiência televisiva. Concebemos um canal televisivo não como simples objeto para análise de programação ou do tipo de conteúdo veiculado, mas como ambiência, 0 que acena para a possibilidade de compreender a experiência televisiva, nos termos de Dewey, com base no processo de incorporação material de um específico modo de formar/fazer/atuar.

Para Dewey (1980), experiência designa a interação (necessária e constante) estabelecida entre um organismo e 0 ambiente, a qual, para além de sua força simbólica, tem pregnância física, ou seja, é algo dotado de dimensões concretas. Experiência, seja aquela rotineira, repetida, dispersa e fragmentada, submissa a convenções, seja aquela definida como "uma", que mobiliza diversas capacidades humanas de maneira integral e intensa (DEWEY, 1980), é sempre ação (física, intelectual e emocional), ato de percepção que envolve interpretação, repertório, padrões, mobilização corpórea; existe em função de um objeto, cuja materialidade, condições de aparição e circunstâncias histórica e social não são indiferentes (GUIMARÃES e LEAL, 2008, p. 06). Nesses termos, a televisão é tomada enquanto ambiência - ou figuração da experiência (GUIMARÃES e LEAL, 2008) -, cujas condições materiais e simbólicas têm nos gêneros televisivos estratégias centrais de comunicabilidade.

Dimensão de interação entre produtos midiáticos e práticas sociais, a noção de gênero vem ganhando espaço no campo da comunicação enquanto conceito metodológico, o que pressupõe considerá-lo não como instância abstrata ou algo dotado de natureza intrínseca, mas categoria analítica cuja validade é provada por existências empíricas reconhecidas historicamente. Gêneros midiáticos são práticas culturais encarnadas em formas midiáticas; resultado de articulações entre elementos expressivos, discursivos, hábitos de consumo, estratégias comerciais (JANOTTI Jr, 2005). Tomando como referência o campo televisivo, tal premissa nos leva a interpretar os programas não pela sua concepção como amostra de uma tipologia de programação, mas como processo de produção de sentido. 
Nas palavras de Mittell (2001), convenções de gênero não são definidas e institucionalizadas apenas pelos textos, elas emergem também de relações intertextuais entre os domínios textuais, das indústrias, audiências, política, tecnologia, crítica, etc. 0 autor desloca 0 sentido de gênero da ideia de consenso, quando o define como categoria cultural, cenário de disputa de sentidos. Regularidades genéricas, que restauram competências da audiência, não se organizam, ao longo do tempo, de modo linear, cronológico, dedutivo e estático, mas são construídas por um contínuo processo de dispersão. São permanentemente ressignificadas, atuam em uma espécie de espiral de elementos textuais e contextuais, que põem em jogo disputas de sentidos em torno de uma formação estável, a qual seria seu reconhecimento e modos de recepção em um determinado tempo-espaço.

Em termos metodológicos, pode-se afirmar que a força do gênero, quando pensado para a análise televisiva, passa pela possibilidade de relacionar, em diferentes sistemas (programas, críticas e reportagens, material publicitário, depoimentos de produtores e espectadores, premiações, etc.), regularidades e desvios de sentido que respondem pelas formas como a TV se constrói enquanto dimensão ativa da sensibilidade. Nessa direção, o conceito pode ser posto em funcionamento para identificar elementos, ordem, correlações, posições, funcionamentos e reconfigurações que nos levem a compreender modos de formar de uma determinada emissora a partir de suas estratégias de restauração e rasura de convenções. Tal proposição nos desafia a apropriar o sentido de performance para 0 exame das maneiras específicas de interação entre uma ambiência midiática e sua recepção.

Apesar de não se relacionar especificamente com 0 audiovisual, a noção de performance parece se mostrar como um profícuo legado para a compreensão desse caráter performativo de um canal televisivo. Com o conceito, Zumthor (2000) procurou avançar em um entendimento inicial de que todo texto pressupõe um corpo performático implícito, atacando as possibilidades de experiências inscritas nos textos como indicadores de leitura. Os textos teriam indícios da experiência que remetem, ao mesmo tempo, a um padrão estável e a uma força inventiva. Simon Frith (1998), no campo específico da música popular massiva, caracteriza 0 ato de ouvir enquanto performance quando afirma que a canção reproduz um dado saber cultural, indicando formas de ouvir e de interagir.

\section{0 interesse de Frith é pensar a performance} como uma experiência de sociabilidade, o que serve de inspiração para Cardoso Filho (2014), ao analisar as manifestações materiais da banda Pink Floyd enquanto performance, argumentar que 0 corpo, o movimento, os gestos fazem parte de uma conduta mais ampla que se desenvolve em virtude da experiência cultivada da tradição do rock e da carreira da banda (2014, p.214). Nesse mesmo sentido, acredita-se que as formas 
materiais de um específico programa e dos modos de convocação dos gêneros midiáticos podem nos dar pistas para a compreensão de uma conduta mais ampla que diz sobre a experiência com uma determinada marca/organização televisiva, a qual evoca reiteração de determinados padrões estáveis e suas desestabilizações.

Essa proposição encontra fundamento em Richard Schechner (2006), que, ao conceber a performance como um "mostrar fazer", amplifica a abordagem assumindo que esta pode ser pensada como toda atividade humana (na vida cotidiana, nas artes, nos negócios, nas tecnologias, etc.). Para ele, a possibilidade de acesso a essa dimensão estaria no sentido de comportamentos restaurados (restored behaviors), pelos quais atuam as convenções. Performances são comportamentos restaurados, comportamentos duplamente experienciados, ações realizadas e para as quais as pessoas treinam e ensaiam; práticas repetidas que constituem rituais, situações, identidades, narrativas e novos padrões (SCHECHNER, 2006).

Ora, se performance constitui sentidos através de práticas repetidas e culturalmente reconhecidas, Schechner reconhece que eventos, ações ou comportamentos podem ser examinados "como" performance justamente porque estão, sempre, em processo. 0 sentido de processo e a ênfase dada às noções de convenção, competência e situação cultural são pontos centrais da nossa argumentação em direção ao diálogo com os cultural studies.
Comecemos por Raymond Williams, para quem a análise cultural parte do reconhecimento do processo de transformações permanentes que implicam em alterações das formas materiais e simbólicas e dos modos de pensar, alterações que têm o sentido de convenção como chave analítica. Por essa acepção, a TV é uma forma cultural e também instituição social, pela qual operam tradições, as forças dominantes que ditam o que deve ser reiterado, valorizado e silenciado em um determinado tempo-espaço, e formações, as tendências (científicas, filosóficas, estéticas, ideológicas, etc.) do desenvolvimento ativo da cultura (WILLIAMS, 1979), que também dizem sobre modos de reconhecimento, repetição e subversões de padrões. Pela hipótese da estrutura de sentimento, 0 autor procura encontrar uma possibilidade conceitual que responda por essa relação que temos com a vida ordinária, em termos do que é experienciado e do que é da ordem do instituído. Apresenta um caminho para fisgar a maneira como vivemos a complexidade das relações entre materialidades econômicas, estruturas sociais e a produção de sentido (GOMES, 2011, p.38).

A ideia de convenção, que não equivale, mas se aproxima do sentido de comportamento restaurado, atua como chave para captar formas possíveis de lidar e se articular com o instituído, reiterando, disputando e formando novos padrões. Por convenção, entendem-se formas de expressão que são, ao mesmo tempo, consenso tácito e padrão partilhado no presente (HIGGINS, 2005). 0 sentido de hipótese dado à noção de 
estrutura de sentimento torna-se mais claro quando Williams supõe que as mudanças nas convenções (as quais não são meramente causais, frutos de escolhas técnicas, mas processuais e históricas) se relacionam com mudanças nos valores, gostos, formas que respondem por modos de vida. Analisar historicamente esse processo (de formação de convenções, que, arriscamos dizer, irão orquestrar os chamados comportamentos restaurados) significa dar conta de distintas temporalidades em um mesmo tempo histórico.

Dominante, residual e emergente são categorias apropriadas por Williams para descrever as diferentes temporalidades que configuram um processo de formação cultural. 0 elemento dominante seria o hegemônico, não no sentido de dominação, mas de forças (valores, sentidos, formas, etc.) prevalentes. Os aspectos residuais são aqueles construídos em um tempo passado, mas que ainda atuam no presente, por isso permitem observar 0 que foi sendo incorporado e reincorporado como hegemônico. 0 residual é diferente do arcaico, que seria um aspecto reconhecido como "do passado", que não persiste como convenção do presente. Já os elementos emergentes seriam significados, práticas, gostos que estão sendo continuamente recriados e que têm a cultura dominante como dimensão de resistência (WILLIAMS, 1979, p.126).
0 emergente se diferencia do novo pelo fato de atuar em emergência (e, portanto, ainda não cristalizada) na disputa pelo consenso ${ }^{2}$.

As pistas apontadas por Williams (1979) relativas à aproximação de estrutura de sentimento com as diferentes temporalidades (dominante, residual e emergente) são interpretadas por Gomes (2011) como dimensões de análise da cultura. Quando põe 0 conceito de gênero como categoria cultural em funcionamento para análise televisiva, a autora leva a cabo a proposta ao considerar esses três elementos como formas de acessar o que é instituído socialmente como convenção, articulado ao que é da ordem da experiência cotidiana, como modo de recuperar historicamente, pela interpretação de elementos dominantes e residuais, as fissuras da ordem do vivido. Em seu estudo, Gomes se refere especialmente às práticas culturais do telejornalismo, tomado como gênero televisivo, mas sua abordagem inspira leituras de outras dimensões midiáticas, como o rock, as séries televisivas, os quadrinhos, etc.

Estrutura de sentimento e gênero como categoria cultural nos oferecem insumos para sustentar que formas expressivas que orientam o consumo midiático são frutos de um contínuo processo de restauração e ressignificação de convenções.

Williams tinha, notadamente, a preocupação, de fundo marxista, em analisar a cultura como estratégia para identificar outras construções (alternativas e oposicionais) de organização social frente ao capitalismo. Quando nos apropriamos de seus pressupostos para o exame da performance televisiva, o esforço é na direção de fisgar transições e deslocamentos de sentidos, valores e práticas de produção e recepção de modo a observar como uma determinada estrutura tem sido vivida. Ocupando um lugar distinto de análise, esta proposta da abordagem histórica da TV se inspira em Williams para questionar: quais elementos da cultura nos permitem falar da MTV Brasil em diferentes momentos históricos com base nas apropriações e ressignificações de convenções? 
Tal pressuposto parece fundamental para um olhar sobre a TV que leve em conta relações entre textos e contextos e privilegie uma abordagem historicizada das emissoras, dos gêneros, dos usos da linguagem, das narrativas, dando conta de suas distintas temporalidades. Estudar como, historicamente, reconhecemos e nos relacionamos afetivamente com um canal televisivo pressupõe uma análise que 0 considere espaço de disputa de padrões e valores implícitos e explícitos que conformam, por práticas repetidas, um específico modo de vida, uma específica cultura.

Nessa mesma perspectiva, a noção de performance enquanto um "mostrar fazer" (SCHECHNER, 2006), ou "indícios da experiência" que nos dizem sobre modos de leitura (ZUMTHOR, 2000), inspira a possibilidade de compreensão de formas expressivas de uma emissora, cujo reconhecimento advém de convocações e também rasuras de convenções (aqui apropriadas enquanto marcas de gênero). Isso porque entendemos que a história cultural da TV - dos seus modos específicos de interação com a recepção e suas formas reconhecidas de constituição de realidades - é um processo contínuo, repetido, dinâmico e também simultâneo de naturalizações e desnaturalizações, dominâncias e rupturas, de convenções e disputas por novas convenções.

\section{Por que falar de performance da MTV Brasil?}

Fundada em 1981 como um canal a cabo norteamericano, a Music Television começou a ser veiculada no Brasil em 20 de outubro de 1990, pelo Grupo Abril, como primeiro canal segmentado do país. Foi a terceira franquia da multinacional, a primeira a ser lançada em TV aberta e em outra língua que não o inglês. Circulou em sinal UHF até o seu fechamento, em 30 de setembro de 2013, quando foi devolvida para a proprietária da marca, a programadora norte-americana Viacom.

Ao analisar a consolidação da indústria fonográfica internacional, Burnett (1996) afirma que, com a MTV, a música pop foi incorporada pela TV e, ao mesmo tempo, incorporou sua forma visual. Em termos locais, a repercussão nacional da emissora ratificou seu impacto mundial: fomentou o mercado audiovisual, ampliou 0 consumo de música jovem, em especial o rock, fato que incentivou o surgimento de bandas e selos de gravadoras (JANOTTI Jr., 2003, p.59). Durante a década de 1990, quando as formas de acesso ao consumo de rock se reduziam a publicações impressas e poucas rádios dedicadas ao gênero, firmou-se como agente de um cenário fonográfico em que as gravadoras multinacionais representavam a força articuladora da cadeia produtiva musical. A exibição de videoclipes financiados pelas majors possibilitava a oferta de conteúdo regular, 0 que levou à instituição do consumo ininterrupto da programação televisivafoi o primeiro canal brasileiro a ser exibido 24 horas seguidas. Assim, também configurou ambiência criativa para o campo televisivo, formando apresentadores, experimentando 
linguagens, reinventando marcas de gêneros televisivos, instituindo convenções estilísticas, etc.

Na primeira década, tinha o rock e 0 videoclipe como dispositivos de distinção. Formas expressivas reconhecidas como "da MTV" se articulavam ao videoclipe (o grafismo, 0 ritmo frenético da edição, as variações de cores e texturas das imagens, os enquadramentos inusitados, etc.), em uma perspectiva de contraste com os gêneros priorizados pelas outras emissoras. Marcas, também genéricas, relativas ao rock situaram um espaço por onde circulavam padrões valorativos, gostos e afetos ligados a um determinado "olhar grupal" (JANOTTI Jr., 2003). Entre 1991 e 1998, por exemplo, no horário da tarde, quando o hábito de audiência brasileira era reconhecido pelos programas de culinária, filmes, talk shows e debates em torno de temas da vida ordinária (casamento, traições, fofocas, etc.), o programa Gás Total, apresentado por Gastão Moreira, exibia clipes de bandas de rock pesado e entrevista com artistas da cena rocker brasileira. Programas como Fúria Metal, dedicado às variadas vertentes do heavy metal, Lado $\mathrm{B}$, voltado para o universo do rock alternativo pouco divulgado na grande mídia, e Clássicos MTV, com foco em videoclipes de bandas como Led Zeppelin, Black Sabbath e The Who, demarcavam lugar de diferenciação, em território nacional, da emissora norte-americana.

Esse "olhar grupal" se amparava nas disputas valorativas em torno da definição do rock pelo sentido de autenticidade (FRITH, 1998), apropriado como critério de distinção de produção televisiva. Em termos retóricos, é possível compreender esse modo de se mostrar da MTV, que se relaciona e constitui seu "olhar grupal", por uma série de oposições relacionadas ao valor de autenticidade: mainstream e independência, popular e segmentado, autêntico e cooptado, etc. Era como se as instâncias do processo comunicativo fossem constituídas pela oposição entre nós (a MTV e seus interlocutores) e eles (as outras emissoras, seus programas, consumidores e modos de reprodução dos gêneros) (GUTMANN, 2014).

Um aspecto característico do canal foi sua personalização construída pela figura do VJ (Video-jockey), o apresentador que, pelo uso do seu corpo e um específico mise-en-scéne, constrói pontos de identificação com a audiência (GOODWIN, 1992). A partir do estudo de John Langer's sobre as construções de personalidades televisivas via hierarquia de identificação, Goodwin argumenta que, enquanto os artistas de rock presentes na programação são colocados como "estrelas", os VJs seriam "0 ordinário". Tal suposição decorre de uma análise comparativa entre o cinema, que representaria um mundo habitado por alguém "fora dali", e a televisão, que se configura como algo doméstico, íntimo e acessível. Em uma remissão a Martín-Barbero (2008), reconhecemos, nessa formulação, dispositivos convencionais da mediação televisiva, como a simulação do contato e a retórica do direto. Pelo primeiro, a TV se relaciona com 
um determinado grupo social, fazendo-o de interlocutor. Como modo de acionar o tempo disperso e o espaço doméstico, investe nas figurativizações do "apresentador-animador" e no tom coloquial das falas. Já a retórica do direto organiza a ambiência televisual sob 0 eixo da proximidade construída com base no tempo simultâneo e fragmentado, típicos da vida cotidiana (MARTÍN-BARBERO, 2008).

Para Goodwin (1992), os VJs, assim como os apresentadores dos noticiários, de talk shows, dos programas de auditório, funcionam como dimensões mediadoras de uma dada realidade televisiva, neste caso, 0 universo das celebridades pop (1992, p. 141). Na MTV, eles personificam, pelo seu corpo, fala, vestimentas e gestos, 0 "olhar grupal" da emissora; forjam modos de reconhecimento pela afirmação de suas relações afetivas com determinados gêneros musicais, obras e artistas.

Frith (1993) analisa a relação entre TV, música e juventude, consolidada globalmente com 0 advento da Music Television, buscando compreender o lugar da "nova" audiência construída pela emissora. A juventude é vista como um grupo social com interesses específicos ligados a determinados comportamentos institucionalizados, ela "não apenas descreve um tipo específico de espectador que é atraído por um tipo específico de programa, mas descreve um tipo particular de comportamento da audiência" (FRITH, 1993, p.75), que contempla reconhecimento de gêneros televisivos e musicais, hábitos e expectativas de consumo, gostos, modos de ser e de dizer, etc.

0 comportamento da audiência, virtualizado (ou restaurado) no processo de interação entre espectadores, programas, vinhetas, mediadores, é uma pista importante para a compreensão da formação cultural da emissora. No caso da MTV Brasil, seus contextos de formação contemplam, especialmente, rearranjos dos modos de consumo da música popular massiva a partir do advento das tecnologias de gravação e reprodução sonora e seu impacto na indústria fonográfica, da popularização da internet e das redes de compartilhamento digital, da institucionalização do hábito de audiência segmentada com a entrada e consolidação de canais de TV pagos no país.

0 ano de 1999 é reconhecido pela crítica televisiva como marco da programação da emissora ${ }^{3}$, quando "deixa de lado a vocação 'alternativa"” para "entrar na briga com as redes de TV aberta" (DECIA, 18 fev. 1999). É o período caracterizado como "abertura" da programação (SORDILI, 04 abr. 1999). Abertura para a "música nacional pop mais comercial" (DECIA, 18 fev. 1999), como o pagode, axé e sertanejo, e para convenções de gêneros 
também ditas "populares"4 da TV brasileira, como o programa de auditório, de variedades, de namoro e o reality show. Em termos comerciais, a MTV Brasil buscava estratégias de interação com uma juventude que não mais a tinha como única possibilidade de acesso audiovisual para o consumo de música. 0 que nos interessa, no entanto, não é seu posicionamento comercial no mercado televisivo (e cada vez menos fonográfico), mas como o canal, pensado enquanto ambiência, buscou se articular, através de seus programas e modos de apropriação de marcas de gênero, ao "novo" sensorium, que respondia também por outros hábitos, desejos e comportamentos da juventude. Movimento que, ao contrário do que caracterizou a imprensa na época, não se reduz à simples ruptura (com o rock e com o videoclipe), mas se explica por um contínuo processo de transições, em que o sentido de autenticidade é disputado como marca discursiva de distinção.

O Supernova (1999-2002) foi reconhecido como marca desta "virada", a "mais radical dos nove anos de MTV Brasil" (DECIA, 18 fev. 1999). 0 programa entrou na faixa de programação no lugar de diversos produtos especializados em música da emissora, entre os quais Clássicos MTV e Gás Total. As atrações mais segmentadas (com foco no techno, rap, metal e alternativo) foram para a meia-noite. 0 novo produto era identificado pela crítica como programa de "clipes e variedades"
(VITÓRIA, 21. Fev. 2000), que "mistura música, jornalismo, vinhetas e comerciais em uma grande salada" (DECIA, 18 fev. 1999). No seu primeiro ano de veiculação, quando foi exibido em quatro edições diárias, eram explícitas as disputas entre artistas considerados "autênticos" e os "cooptados", entre os públicos "aficionados pela música" e os "fãs das celebridades", entre os apresentadores "tradicionais" e os "novos" VJs da emissora. 0 Supernova 2, edição mais longa veiculada das $14 \mathrm{~h}$ às $15 \mathrm{~h} 30$ e única previamente gravada, era apresentado por Chris Nicklas, a VJ substituta do programa mais popular da emissora (o Disk MTV), e abria espaço para pagode, sertanejo e axé. Já a última, das 20h30, veiculava videoclipes de rock - principalmente das bandas denominadas indie, como Radiohead - e de artistas nacionais considerados autênticos, como o grupo Nação Zumbi. A edição noturna foi apresentada por Soninha, cuja credibilidade era reconhecida, até então, pela trajetória marcada por programas informativos e de debate. 0 Supernova inaugura os cenários físicos na MTV Brasil, com elementos cênicos típicos da TV aberta (bancada, computador, assentos para os convidados e entrevistadores), no lugar do cenário eletrônico com fundo em chroma key, próprios dos programas de videoclipe da emissora.

Em 2000, a faixa vespertina passou a ser ocupada por uma única edição do Supernova, apresentado 
pelos VJs estreantes Didi Wagner e Marcos Mion, ao vivo, com três horas de duração. Dava ênfase às novidades do mundo das celebridades, entrevistas com artistas e estreias de videoclipes de axé, pagode, dance music, rock e rap nacional. Se, no primeiro ano, o Supernova construía horários específicos de exibição para os gêneros musicais (os "cooptados" e os "autênticos"), nas edições seguintes do programa a demarcação valorativa era antecipada por sua vinheta. A mais conhecida trazia a imagem de um boneco dançando um funk (a letra dizia: "andamos de ré, viemos pegar mulher..."), que era surpreendido por um soco na cara dado por um segundo boneco, que fazia sua cabeça voar. 0 golpe coincidia com a entrada da vinheta sonora do programa.

No cenário do Supernova, o computador passou a ocupar lugar central, e a conversação - entre os mediadores, entre eles e seus convidados, entre eles e o público através de ligações telefônicas e e-mails constituía a principal estratégia de comunicabilidade. Nessa direção, a MTV vai construindo aproximações com convenções genéricas dessa faixa horária da TV aberta, os programas populares de talk shows reconhecidos pelo protagonismo da vida ordinária e do sujeito espectador.

Essa breve descrição dos primeiros anos de exibição do Supernova indica que a história cultural da MTV Brasil não se explica por momentos episódios de "mudanças", mas por um contínuo processo de disputas entre valores e sentidos que são da ordem de continuidades e descontinuidades dos modos de relação com as audiências (aqui vistos pelas formas de expressão e valoração dos gêneros musicais e televisivos). No mesmo ano em que lança o Supernova e inclui 0 axé e o pagode como categorias do seu principal instrumento de consagração do campo musical, o $\mathrm{VMB}^{5}$, programas como Mondo Massari (1999-2000), apresentado pelo cultuado VJ Fábio Massari, são referendados pela imprensa especializada. "Estréia que nasce na contracorrente da política perpetrada pela emissora neste ano, a de olhar para 0 umbigo da produção nacional e privilegiar 0 axé e 0 pagode", pois dava foco para "a produção alternativa feita nas partes 'esquecidas' do mainstream sonoro e visual" (RIBEIR0, 22 out, 1999). Tal definição indica um cenário de disputa em torno do sentido de autenticidade que marcou, historicamente, modos de fazer e se mostrar da emissora.

\section{RIP MTV Brasil ou para onde apontam as considerações finais}

Essa leitura de parte do processo de formação cultural da MTV Brasil, com foco nas continuidades e descontinuidades de convenções (padrões culturais de repetição) de gêneros midiáticos (televisivos e musicais), não se mostrou de modo cronológico, linear, fragmentado e causal, mas em um movimento 
de transição contínua, de disputas de sentidos e articulação entre distintas temporalidades. Temporalidades que, em uma perspectiva histórica, nos fazem ver a autenticidade como elemento de distinção da emissora.

Se 0 rock e 0 videoclipe atuaram, em um primeiro momento, enquanto dispositivos de constituição de subjetividades relacionadas a determinado grupamento juvenil, quando a emissora se desloca em direção às referências mais hegemônicas da TV aberta e de outros gêneros musicais, reconfigura seus modos de acesso ao valor de autenticidade como forma de se relacionar com outras juventudes em um outro tempo. Movimento que, como procuramos demonstrar aqui, não se define por uma simples ruptura, mas por um contínuo processo de naturalizações e desnaturalizações. Na virada do século, abriu espaço para artistas de pagode, axé e sertanejo, mas construiu molduras de distinção para eles na sua programação. Ao mesmo tempo que incorporou, em um gesto mesmo de cooptação, convenções televisivas dos programas de humor e talk shows, seu mostrar fazer preservou traços de oposição em relação aos outros canais, seja na maneira escrachada como configurava, por exemplo, o Gordo a Gogo (2000-2005), um dos talks shows mais cultuados da TV brasileira, ou nos modos de constituição do humor a partir da ideia de tosco, que marcaram a programação dos últimos anos do canal.

Nesse sutil movimento que alterna elementos de cooptação e disputas por autenticidade, reside a tentativa - talvez equivocada - de a emissora se engajar em uma dimensão do popular para se relacionar com uma juventude que, a esta altura, já não precisava da MTV para consumir música, já não precisava da MTV para discutir comportamento, política e sexualidade. Arrisco afirmar, ainda em tom meramente especulativo, que a MTV pode ter chegado ao fim não simplesmente por ter perdido sua aura rocker ou por ter incorporado convenções da TV aberta, mas por uma incapacidade de reinventar seus padrões de repetição diante de tantos segmentos, diante de tantas ofertas, diante de tantas outras possibilidades de acesso musical e audiovisual, diante de tantas outras juventudes.

Tal constatação nos leva a investir no protocolo analítico apresentado neste artigo - pautado na articulação entre a noção de performance, gênero midiático e estrutura de sentimento - como possibilidade de compreensão, em uma perspectiva histórica e cultural, dos modos de executar de uma ambiência televisiva através do exame de reiterações de padrões estáveis e suas desestabilizações, vistas no marco de suas materialidades.

\section{Referências}

BURNETT, Robert. The Global Jukebox - The international music industry. London and New York: Routledge, 1996.

CARDOSO FILHO, Jorge. Ao vivo em Pompéia ou no lado escuro da lua? Heranças da performance do Pink Floyd. In: PICAD0, Benjamim; MENDONÇA, Carlos M. C. Mendonça; CARDOSO FILHO, Jorge. Experiência 
estética e performance. Salvador: Edufba, 2014. 236 p. $213-234$.

DECIA, Patrícia. 0 pagado da emetevê. Folha de São Paulo, São Paulo, 28 de Fevereiro de 1999. TV Folha.

MTV adere a pagode e axé em

"Supernova". Folha de São Paulo, São Paulo, 24 de Fevereiro de 1999. Ilustrada.

DEWEY, John. Art as experience. Nova York: Perigee Books, 1980.

FRITH, Simon. Youth/Music/Television. In: FRITH, Simon; G00DWIN, Andrew; LAWRENCE, Grossberg. Sound and Vision - The music video reader. London and New York: Routledge, 1993. p. 57-72

Performing Rites: on the value of popular music. Cambridge / Massachusetts: Harvard University Press, 1998.

GOMES, Itania M. M. Raymond Williams e a hipótese cultural da Estrutura de Sentimento. In: JANOTTI, Jr; GOMES, Itania Maria Mota. Comunicação e Estudos Culturais. Salvador, EDUFBA, 2011. 197 p.29-48 G00DWIN, Andrew. Dancing in the distraction factory: music television and popular culture. Minesota: University of Minesota Press, 1992.

GUIMARÃES, César; LEAL, Bruno S. Experiência estética e experiência mediada. Intexto. Porto Alegre, v.2, n 19, p. 1-14-dez, 2008.

GUTMANN, Juliana. Quando ruptura é convenção: 0 programa Gordo a Go-Go como espaço de experiência do talk show. Contracampo, Niterói, n. 31, p. 60-78, Dez/Marc., 2014.

\section{Jornal da MTV em três}

versões: gênero e modo de endereçamento como estratégias de mediação musical. Dissertação. Salvador, BA: Universidade Federal da Bahia, Programa de Pós-Graduação em Comunicação e Cultura Contemporâneas, 2005.
HIGGINS, John. The Raymond Williams Reader.

0xford: Blackwell Publishers, 2005.

HOLZBACH, Ariane D. Smells Like Teen Spirit: a consolidação do videoclipe como gênero áudio-visual. Tese. Rio de Janeiro: Pós-Graduação em Comunicação da Universidade Federal Fluminense, 2013.

\section{JANOTTI Jr, Jeder. Aumenta que isso aí é Rock} and Roll: mídia, gênero musical e identidade. Rio de Janeiro: E-papers, 2003.

. Dos gêneros textuais, dos discursos e das canções: uma proposta de análise da música popular massiva a partir da noção de gênero midiático. In: XIV Encontro Nacional da COMPÓS, 2005. Rio de Janeiro. Anais... Rio de Janeiro: UFF, 2005.

KOSSELLECK, Reinhart. Futuro Passado:

contribuição à semântica dos tempos modernos. São

Paulo: Contraponto, 2006.

LUSVARGUI, Luisa Cristina. MTV Brasil - a padronização da cultura na mídia eletrônica. Dissertação. São Paulo: Programa de Pós-graduação em Ciências da Comunicação, Escola de Comunicação e Artes da Universidade de São Paulo, 2002.

MARTÍN-BARBERO, Jesús. Dos meios às mediações: comunicação, cultura e sociedade. $5^{\mathrm{a}}$ ed. Rio de Janeiro: Editora UFRJ, 2008.

MITTELL, Jason. A cultural approach to television genre. Cinema Journal, 40, n³ 3, Spring, 2001.

MUANIS, Felipe de Castro. As metaimagens na televisão contemporânea: Rede Globo, MTV e suas vinhetas. Tese.

Belo Horizonte: Pós-Graduação em Comunicação Social da Universidade Federal de Minas Gerais, 2010.

REIS, João Augusto Nascimento. Isto não é TV, é

MTV: linguagem da MTV Brasileira. Dissertação. São

Bernardo do Campo, SP: Programa de Pós-Graduação em Comunicação Social da Universidade Metodista de São Paulo, 2006. 
RIBEIR0, Lucio. "Mondo Massari" sintoniza o planeta inteiro na MTV. Folha de São Paulo, São Paulo, 22 out. 1999. Televisão.

SCHECHNER, Richard. Performance Studies: an introduction. New York: Routledge, 2006.

SOARES, Thiago. A construção imagética dos videoclipes: canção, gêneros e performance na análise de audiovisuais da cultura midiática. Tese. Salvador, BA: Universidade Federal da Bahia, Programa de Pós-Graduação em Comunicação e Cultura Contemporâneas, 2005.

SORDILI, Aline. Nova MTV impulsiona produção. Folha de São Paulo, São Paulo. 04. abr. 1999. TV Folha.

TREVISAN, Michele Kapp. A era MTV: análise da estética de videoclipe (1984-2009). Tese. Porto Alegre: Programa de Pós-Graduação em Comunicação da Pontifícia Universidade Católica do Rio Grande do Sul, 2011.

VITORIA, Gisele. Didi, a aposta da MTV. Isto É Gente, São Paulo, 21. Fev. 2000. Retirado de http://www.terra. com.br/istoegente/29/reportagens/rep_adriana.htm WILLIAMS, Raymond. Marxismo e Literatura. Rio de Janeiro: Jorge Zahar, 1979.

ZUMTHOR, Paul. Performance, recepção e leitura.

São Paulo: EDUC, 2000. 
About performance and historicity: an aesthetic and cultural approach of MTV Brazil

\section{Sobre performance $y$ historicidad: un enfoque estético y cultural de MTV Brasil}

\section{Abstract}

This article proposes a conceptual articulation for capture, in a historical perspective, the acting of MTV Brazil, their ways of doing and ways of relating with the audience and cultural contexts, a process translated as televised performance. It examines the TV channel as an environment of televisual experience, consisting by a continuous process of disputes of values and meanings, continuities and ruptures materialized in their programs and ways to convoke genres brands (television genres and musical genres).There is a broader expectation research: discuss procedures for analyzing a media organization based on the articulation between the concepts of genre, performance and structure of feeling to promote a dialogue between the aesthetic and the cultural studies.

\section{Keywords}

Performance. Historicity. MTV Brazil.

\section{Resumen}

Este artículo presenta una propuesta de articulación conceptual para la apreensión, bajo una perspectiva histórica, del desempeño de la MTV Brasil, sus maneras de hacer, de relacionarse com la audiencia y contextos culturales, proceso aqui traducido por la idea de performance televisiva. Examina la red como un ambiente de la experiencia televisiva, constituída por un continuo proceso de disputas por valores y sentidos, por continuidades y rupturas materializado em sus programas y en los modos de convocatória de marcas de género (televisivos y musicales). Se proyecta una expectativa más amplia de investigación: discutir procedimientos para el análisis de una organización mediática por la articulación entre los conceptos de género, performance y estructura de sentimiento como possibilidad de promover diálogo entre la estética y los estúdios culturales.

\section{Palabras clave}

Performance. Historicidad. MTV Brasil. 


\section{Expediente}

A revista E-Compós é a publicação científica em formato eletrônico da Associação Nacional dos Programas de Pós-Graduação em Comunicação (Compós). Lançada em 2004, tem como principal finalidade difundir a produção acadêmica de pesquisadores da área de Comunicação, inseridos em instituições do Brasil e do exterior.

\section{E-COMPÓS I www.e-compos.org.br I E-ISSN 1808-2599}

Revista da Associação Nacional dos Programas de Pós-Graduação em Comunicação.

Brasília, v.18, n.2, maio/ago. 2015.

A identificação das edições, a partir de 2008, passa a ser volume anual com três números.

Indexada por Latindex I www.latindex.unam.mx

\section{CONSELHO EDITORIAL}

Alexandre Rocha da Silva, Universidade Federal do Rio Grande do Sul, Brasil Alexandre Farbiarz, Universidade Federal Fluminense, Brasil Ana Carolina Damboriarena Escosteguy, Pontifícia Universidade Católica do Rio Grande do Sul, Brasil

Ana Carolina Rocha Pessôa Temer, Universidade Federal de Goiás, Brasil Ana Regina Barros Rego Leal, Universidade Federal do Piauí, Brasil André Luiz Martins Lemos, Universidade Federal da Bahia, Brasil Andrea França, Pontifícia Universidade Católica do Rio de Janeiro, Brasil Antonio Carlos Hohlfeldt, Pontifícia Universidade Católica do Rio Grande do Sul, Brasil

Arthur Ituassu, Pontifícia Universidade Católica do Rio de Janeiro, Brasil Álvaro Larangeira, Universidade Tuiuti do Paraná, Brasil Ângela Freire Prysthon, Universidade Federal de Pernambuco, Brasil César Geraldo Guimarães, Universidade Federal de Minas Gerais, Brasil Cláudio Novaes Pinto Coelho, Faculdade Cásper Líbero, Brasil Daisi Irmgard Vogel, Universidade Federal de Santa Catarina, Brasil Daniela Zanetti, Universidade Federal do Espírito Santo, Brasil Denize Correa Araujo, Universidade Tuiuti do Paraná, Brasil Eduardo Antonio de Jesus, Pontifícia Universidade Católica de Minas Gerais, Brasil

Eduardo Vicente, Universidade de São Paulo, Brasil

Elizabeth Moraes Gonçalves, Universidade Metodista de São Paulo, Brasil Erick Felinto de Oliveira, Universidade do Estado do Rio de Janeiro, Brasil Francisco Elinaldo Teixeira, Universidade Estadual de Campinas, Brasil Francisco Paulo Jamil Almeida Marques, Universidade Federal do Ceará, Brasil Gabriela Reinaldo, Universidade Federal do Ceará, Brasil Gisela Grangeiro da Silva Castro, Escola Superior de Propaganda e Marketing, Brasil

Goiamérico Felício Carneiro Santos, Universidade Federal de Goiás, Brasil Gustavo Daudt Fischer, Unisinos, Brasil

Herom Vargas, Universidade Municipal de São Caetano do Sul, Brasil
Itania Maria Mota Gomes, Universidade Federal da Bahia, Brasil Janice Caiafa, Universidade Federal do Rio de Janeiro, Brasil Jiani Adriana Bonin, Universidade do Vale do Rio dos Sinos, Brasil José Afonso da Silva Junior, Universidade Federal de Pernambuco, Brasil José Luiz Aidar Prado, Pontifícia Universidade Católica de São Paulo, Brasil Kati Caetano, Universidade Tuiuti do Paraná, Brasil

Lilian Cristina Monteiro França, Universidade Federal de Sergipe, Brasil

Liziane Soares Guazina, Universidade de Brasília, Brasil Luíza Mônica Assis da Silva, Universidade de Caxias do Sul, Brasil Luciana Miranda Costa, Universidade Federal do Pará, Brasil Malena Segura Contrera, Universidade Paulista, Brasil Marcel Vieira Barreto Silva, Universidade Federal da Paraíba, Brasil Maria Ogécia Drigo, Universidade de Sorocaba, Brasil Maria Ataide Malcher, Universidade Federal do Pará, Brasil Maria Clotilde Perez Rodrigues, Universidade de São Paulo, Brasil Maria das Graças Pinto Coelho, Universidade Federal do Rio Grande do Norte, Brasil

Mauricio Ribeiro da Silva, Universidade Paulista, Brasil

Mauro de Souza Ventura, Universidade Estadual Paulista, Brasil

Márcio Souza Gonçalves, Universidade do Estado do Rio de Janeiro, Brasil Micael Maiolino Herschmann, Universidade Federal do Rio de Janeiro, Brasil Mirna Feitoza Pereira, Universidade Federal do Amazonas, Brasil Nísia Martins Rosario, Universidade Federal do Rio Grande do Sul, Brasil Potiguara Mendes Silveira Jr, Universidade Federal de Juiz de Fora, Brasil Regiane Ribeiro, Universidade Federal do Paraná, Brasil Rogério Ferraraz, Universidade Anhembi Morumbi, Brasil Rose Melo Rocha, Escola Superior de Propaganda e Marketing, Brasil Rozinaldo Antonio Miani, Universidade Estadual de Londrina, Brasil Sérgio Luiz Gadini, Universidade Estadual de Ponta Grossa, Brasil Simone Maria Andrade Pereira de Sá, Universidade Federal Fluminense, Brasil Veneza Mayora Ronsini, Universidade Federal de Santa Maria, Brasil Walmir Albuquerque Barbosa, Universidade Federal do Amazonas, Brasil

\section{COMISSÃO EDITORIAL}

\section{Cristiane Freitas Gutfreind}

Pontifícia Universidade Católica do Rio Grande do Sul, Brasil

Irene Machado

Universidade de São Paulo, Brasil

Jorge Cardoso Filho

Universidade Federal do Reconcavo da Bahia, Brasil

Universidade Federal da Bahia, Brasil

\section{EQUIPE TÉCNICA}

ASSISTENTE EDITORIAL I Márcio Zanetti Negrini

REVISÃO DE TEXTOS I Press Revisão

EDITORAÇÃO ELETRÔNICA I Roka Estúdio

CONTATO I revistaecompos@gmail.com
COMPóS I www.compos.org.br

Associação Nacional dos Programas de Pós-Graduação em Comunicação

Presidente

Edson Fernando Dalmonte

Programa de Pós-Graduação em Comunicação

e Cultura Contemporânea - UFBA

edsondalmonte@uol.com.br

Vice-presidente

Cristiane Freitas Gutfreind

Programa de Pós-Graduação em Comunicação Social - PUC-RS cristianefreitas@pucrs.br

Secretário-Geral

Rogério Ferraraz

Programa de Pós-Graduação em Comunicação

Universidade Anhembi Morumbi

rogerioferraraz@anhembimorumbi.edu.br 